\title{
Influences of Vibratory Stresses on Initiation of Stress Corrosion Cracking in High-Strength Steel*
}

\author{
By Kenjiro Komai**, Kohji Minoshima** and Toshihiro Fujito**
}

\begin{abstract}
The stress corrosion cracking (SCC) initiation behavior under a sustained load with small vibratory loads superimposed has been investigated on a high-strength low-alloy steel AISI 4135 sensitive to hydrogen embrittlement (HE) type SCC immersed in $3.5 \% \mathrm{NaCl}$ solution at both the free corrosion potential and the cathodically charged potential at $E=-1.0 \mathrm{~V}$ (SCE). At the free corrosion potential, the time to crack initiation with small vibratory stresses superimposed is shorter than that of static SCC with lower $600 \mathrm{ks}$ strength than $\sigma_{\mathrm{SCC}}$ for static SCC. At $\Delta \sigma \leqq 74 \mathrm{MPa}$, however, the effects of superimposed stresses on $600 \mathrm{ks}$ strength are negligible with the same value as $\sigma_{\mathrm{SCC}}$. At $\sigma_{\max }>\sigma_{\mathrm{SCC}}$, SCC cracks are initiated at the corrosion pits formed on specimen surfaces. At $\sigma_{\max }<\sigma_{\mathrm{SCC}}$ and $\Delta \sigma>74 \mathrm{MPa}$, however, superimposed vibratory stresses promote stress-assisted crack-like dissolution preceded by corrosion pits; dynamic SCC cracks are initiated at the bottom of crack-like defects, resulting in the lower dynamic SCC strength. $K_{\text {ISCC }}^{*}$, which is obtained by assuming the corrosion pits and the crack-like defects to be sharp cracks, is roughly equivalent to $K_{\text {IScC }}$ obtained by long, sharp crack specimens. When the cathodic potential is applied to specimens, the effects of superimposed small vibratory stresses on the $600 \mathrm{ks}$ strength are negligible, because the metal dissolution reaction is inhibited. In such cases SCC cracks are initiated at the interior of specimens where the triaxial stress is maximum.
\end{abstract}

(Received August 9, 1985)

Keywords: stress corrosion cracking, crack initiation, vibratory stresses, high-strength steel, effect of cathodic potential

\section{Introduction}

High-strength materials are sensitive to environments, and their environmentally induced degradation including stress corrosion cracking (SCC) poses serious problems. It is well known that the fracture mechanics provides a quantitative tool for correlating SCC crack growth rates. However, we must pay more attention to the SCC crack initiation behavior on smooth surfaces in such cases that incubation to crack initiation takes a lot of time.

Machines and structures are often subjected to small vibratory loads superimposed on a sustained load. We have previously reported that such dynamic loads enhance crack growth rates and reduce threshold stress intensity factors in materials sensitive to hydrogen embrittlement $^{(1)}(\mathrm{HE})$ and active path corrosion ${ }^{(2)(3)}$ (APC) type SCC, and have proposed the con-

* This paper was originally published in Japanese in J. Japan Inst. Metals, 48 (1984), 307.

* Department of Mechanical Engineering, Faculty of Engineering, Kyoto University, Kyoto 606, Japan. cept of dynamic SCC. SCC crack initiation is also considered to be affected by such small vibratory stresses. Nakasa and co-workers ${ }^{(4)(5)}$ reported that the time to SCC crack initiation of a high-strength steel of notched specimens was shortened by small vibratory stresses and its strength was lowered.

In the present investigation, the SCC crack initiation behavior under a sustained load with and without small vibratory stresses superimposed has been investigated in a high-strength steel AISI 4135. The SCC crack initiation mechanisms under dynamic loading conditions have been discussed, and the basic data for using high-strength materials in aggressive environments have been obtained.

\section{Experimental Procedures}

The material tested was a high-strength steel AISI 4135, whose chemical composition, heat treatments and mechanical properties are listed in Tables 1, 2 and 3, respectively. Smooth specimens shown in Fig. 1 were used. The specimens were finally finished with diamond 
Table 1 Chemical composition of 4135 steel, (mass \%).

\begin{tabular}{ccccccc}
\hline \hline $\mathrm{C}$ & $\mathrm{Si}$ & $\mathrm{Mn}$ & $\mathrm{P}$ & $\mathrm{S}$ & $\mathrm{Cr}$ & $\mathrm{Mo}$ \\
\hline 0.37 & 0.26 & 0.74 & 0.022 & 0.020 & 1.07 & 0.18 \\
\hline \hline
\end{tabular}

Table 2 Heat treatments of 4135 steel.

\begin{tabular}{ccc}
\hline \hline Normalizing & Quenching & Tempering \\
\hline $1143 \mathrm{~K}, 1.8 \mathrm{ks}$ & $1128 \mathrm{~K}, 1.8 \mathrm{ks}$ & $673 \mathrm{~K}, 3.6 \mathrm{ks}$ \\
Air cooling & Oil quenching & Water cooling \\
\hline \hline
\end{tabular}

Table 3 Mechanical properties of 4135 steel.

\begin{tabular}{ccc}
\hline $\begin{array}{c}0.2 \% \text { offset } \\
\text { yield strength }\end{array}$ & Tensile strength & Elongation \\
\hline $1560 \mathrm{MPa}$ & $1700 \mathrm{MPa}$ & $10 \%$ \\
\hline
\end{tabular}



Fig. 1 Shape and dimensions of test specimens (4135 steel). All dimensions are in $\mathrm{mm}$.

paste $1 \mu \mathrm{m}$ in size after polishing with $\# 2000$ emery papers. A corrosive environment was $3.5 \% \mathrm{NaCl}$ solution, which was kept at $298 \pm 0.5 \mathrm{~K}$ by a thermoregulator and was circulated between a corrosion chamber and a corrosion reservoir at a flow rate of $33 \mathrm{~cm}^{3} / \mathrm{s}$. SCC tests were carried out at the free corrosion potential, $E=E_{c}$, and the cathodically charged potential at $E=-1.0 \mathrm{~V}$ vs $\mathrm{SCE}$, a saturated calomel electrode. A $49 \mathrm{kN}$ electrohydraulic fatigue testing machine was employed. The axial stress wave form was sinusoidal, and the stress cycle frequency $f$ was $30 \mathrm{~Hz}$. The vibratory stress range, $\Delta \sigma$, was varied from $49 \mathrm{MPa}$ to $196 \mathrm{MPa}$.

An acoustic emission (AE) monitoring technique ${ }^{(6)}$ was used to detect crack initiation and its propagation; an $\mathrm{AE}$ sensor (a piezoelastic transducer whose resonance frequency $f_{0}$ was $450 \mathrm{kHz}$ ) was attached to the specimen, as was shown in Fig. 1. Figure 2 shows the $\mathrm{AE}$ monitoring system. After the suitable amplification $(=40 \mathrm{~dB})$ by the " $40 \mathrm{~dB}$ AMPL", AE signals were fed to a discriminator, "DSCRM", where the signals were compared with the threshold voltage $(=50 \mathrm{mV})$. Two techniques were used to eliminate noise signals: one was Sondergeld's logic unit ${ }^{(6)}$, "Sondergeld LOGC CKT", which worked on two variables, counting time $(12.3 \mu \mathrm{s})$ and a selected number of AE signals (=3); the other was "LOGC CKT" which closed the AE counting circuit when a dummy sensor caught electromagnetic split-like noises. Then AE event count rates were measured by a rate meter, "RT MTR", using the dead time technique (dead time $=1.5 \mathrm{~ms}$ ), and was recorded by a strip chart recorder, "RCDR". An AE signal wave was observed by using a digital memory scope, "DGTL MEM'.

\section{Experimental Results and Discussion}

\section{AE event count rate and crack initiation}

Figure 3 shows AE signals observed in the interrupted dynamic SCC test at $\sigma_{\max }=1470$ $\mathrm{MPa}$ and $\Delta \sigma=196 \mathrm{MPa}$; the specimen was automatically unloaded when AE event count

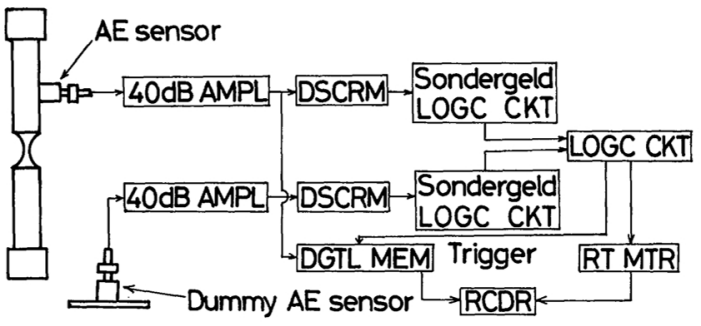

Fig. 2 Block diagram of AE monitoring system.

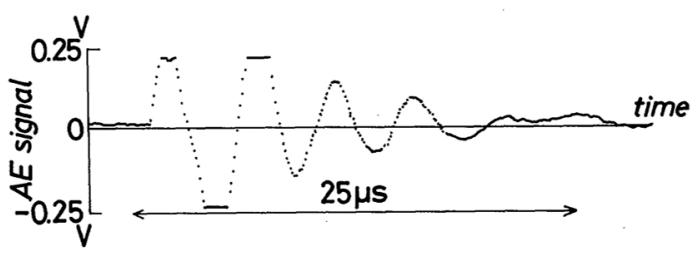

Fig. 3 Observed AE signals; $E=E_{c}, f=30 \mathrm{~Hz}, \sigma_{\max }=$ $1470 \mathrm{MPa}$ and $\Delta \sigma=196 \mathrm{MPa}$. 


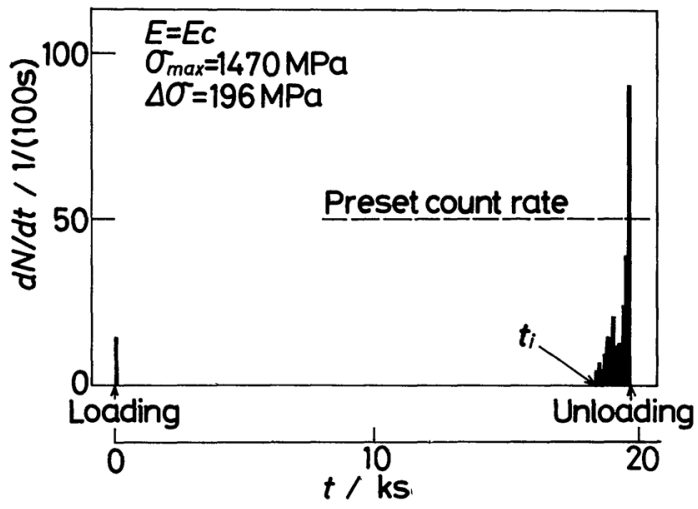

Fig. 4 Variations of $\mathrm{AE}$ event count rates, $d N / d t$, with the lapse of time; $E=E_{c}, f=30 \mathrm{~Hz}, \sigma_{\max }=1470 \mathrm{MPa}$ and $\Delta \sigma=196 \mathrm{MPa}$.

rates, $d N / d t$, exceeded the present value of 50 counts $/(100 \mathrm{~s})$. In this experiment, only burst type AE signals shown in the figure were observed. Figure 4 illustrates the variations of $d N / d t$ with the lapse of time, which were observed in the same specimen shown in Fig. 3. AE signals came out just after the specimen was loaded, nevertheless AE signals were not observed for most of testing duration. However, $d N / d t$ suddenly increased at $t=t_{i}$. This kind of AE behavior was observed irrespective of loading conditions or cathodic protection.

Figure 5 shows a surface crack obtained after the specimen was unloaded. This surface crack measured about $1.8 \mathrm{~mm}$ in length and about $0.9 \mathrm{~mm}$ in depth. Consequently, a sudden increase in $d N / d t$ after $t=t_{i}$ was correlated with crack initiation and its propagation; the crack initiation time was determined at $t=t_{l}$ by the AE monitoring technique. Moreover, most of testing period was spent in incubation time to crack initiation.

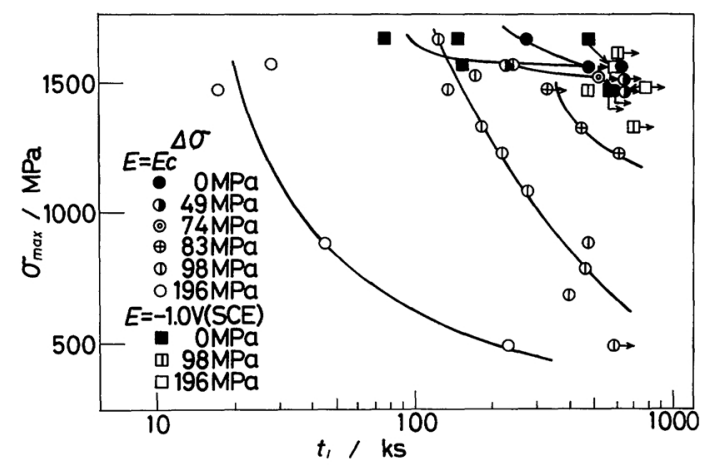

Fig. 6 Relation between $\sigma_{\max }$ and time to crack initiation, $t_{l}$.

\section{Relation between maximum stress and time to crack initiation}

Figure 6 shows the relation between maximum stresses, $\sigma_{\max }$, and time to crack initiation, $t_{i}$, determined by the $\mathrm{AE}$ monitoring technique. At the free corrosion potential, $E=E_{c}$, the time to crack initiation $t_{i}$ under a sustained stress with small vibratory stresses superimposed was shorter than that of static SCC under a sustained stress; the larger the superimposed vibratory stress range was, the shorter the time to crack initiation was. The static SCC strength at $t=600 \mathrm{ks}\left(=10^{4} \mathrm{~min}\right)$, $\sigma_{\mathrm{SCC}}$, was about $1530 \mathrm{MPa}$. At stress ranges smaller than $74 \mathrm{MPa}$, the $600 \mathrm{ks}$ strength was equal to $\sigma_{\mathrm{SCC}}$. At $\Delta \sigma \geqq 83 \mathrm{MPa}$, however, the $600 \mathrm{ks}$ strength was lower than $\sigma_{\mathrm{SCC}}$ : the larger the superimposed vibratory stress range was, the lower the $600 \mathrm{ks}$ strength was.

When the cathodic potential was applied to specimens at $E=-1.0 \mathrm{~V}$ vs $\mathrm{SCE}, \sigma_{\mathrm{SCC}}$ was almost equal to that at the free corrosion potential. At $\sigma_{\max } \geqq \sigma_{\mathrm{SCC}}$, the time to crack initiation at $E=-1.0 \mathrm{~V}$ vs $\mathrm{SCE}$ was shorter than that at the free corrosion potential. However, the

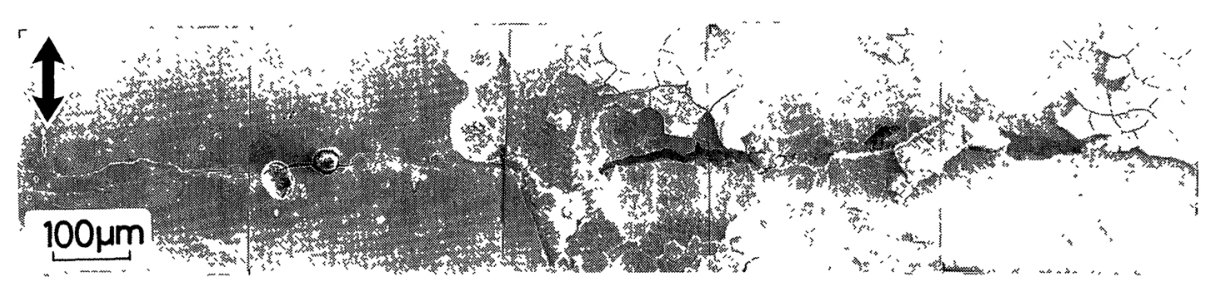

Fig. 5 Surface crack obtained after the AE event count rates approached the present value of 50 counts $/(100 \mathrm{~s}) ; E=E_{c}, f=30 \mathrm{~Hz}, \sigma_{\max }=1470 \mathrm{MPa}$ and $\Delta \sigma=196 \mathrm{MPa}$. Arrow shows the direction of a tensile stress. 
$600 \mathrm{ks}$ dynamic SCC strength was equal to $\sigma_{\mathrm{SCC}}$, when vibratory stresses of $\Delta \sigma=98 \mathrm{MPa}$ and $196 \mathrm{MPa}$ were applied to specimens, and in this case a considerable fall of the $600 \mathrm{ks}$ dynamic SCC strength was observed at the free corrosion potential.

Figure 7 shows an endurance limit diagram, where the ordinate is the amplitude of superimposed stresses, $\Delta \sigma / 2$, and the abscissa the mean stress, $\sigma_{\text {mean }}$, taken from $600 \mathrm{ks}$ SCC strength. At $E=-1.0 \mathrm{~V}$ vs SCE, the effects of superimposed vibratory stresses on endurance limits were negligible: the endurance limits were determined by the straight line of $\sigma_{\max }$ $=$ const. $=\sigma_{\mathrm{SCC}}$ irrespective of superimposed stress ranges. At the free corrosion potential, the effects of the superimposed vibratory stresses were negligible at $\Delta \sigma \leqq 74 \mathrm{MPa}$. At $\Delta \sigma>74 \mathrm{MPa}$, however, a considerable fall of the $600 \mathrm{ks}$ dynamic SCC strength from $\sigma_{\mathrm{SCC}}$ was observed. A small figure in the upper right corner, where both scales of the ordinate and the abscissa are equalized, made the effects of vibratory stresses on the endurance limits more remarkable.

\section{SCC crack initiation sites}

Figure 8 shows a macroscopic fracture surface of dynamic SCC at the free corrosion potential. The crack initiation site is shown by an arrow. The dynamic SCC crack propagated radiately from the initiation site, and a shear lip was formed opposite to the initiation site. The fracture surface of dynamic SCC was normal to the loading axis, and the microscopic



Fig. 7 Endurance limit diagram.

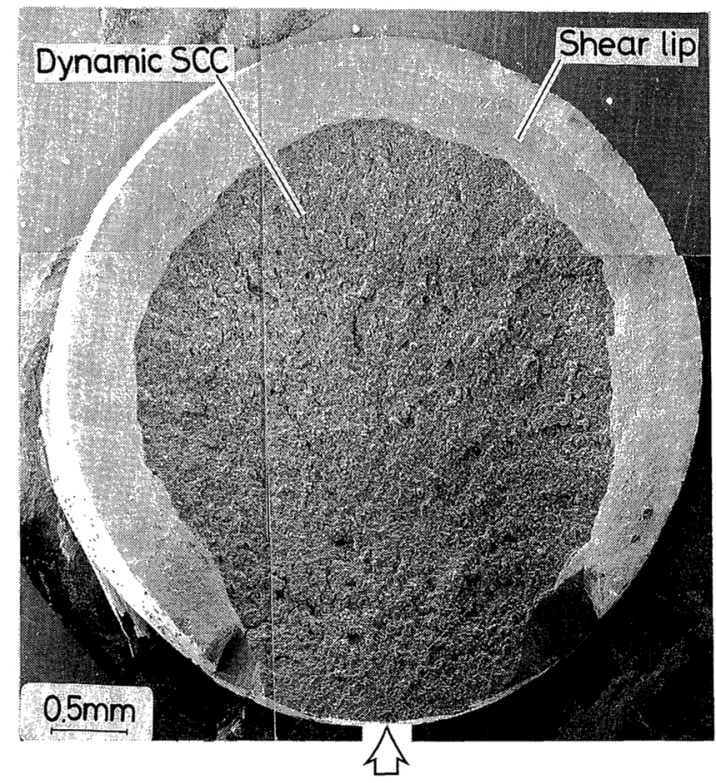

Fig. 8 Macroscopic fracture surface of dynamic SCC at $E=E_{c} ; f=30 \mathrm{~Hz}, \sigma_{\max }=1570 \mathrm{MPa}$ and $\Delta \sigma=196 \mathrm{MPa}$. Arrow shows the initiation site of a dynamic SCC crack.

fracture surface was dominated by intergranular cracking along prior austenite grain boundaries, as had been reported on dynamic $\mathrm{SCC}$ in a high-strength steel ${ }^{(1)}$.

Figure 9(a) shows a matching pair of fractographs of the initiation site for dynamic SCC at $\sigma_{\max } \geqq \sigma_{\text {SCC }}$. Figure 9(b) shows a matching topography across the $\mathrm{A}-\mathrm{A}$ and $\mathrm{A}^{\prime}-\mathrm{A}^{\prime}$ lines of the fracture surfaces shown in Fig. 9(a). These made it clear that the dynamic SCC cracks at $\sigma_{\max } \geqq \sigma_{\mathrm{SCC}}$ were initiated at the bottom of corrosion pits formed on the specimen surfaces.

Figure 10 shows the initiation site of dynamic SCC at $\sigma_{\max }<\sigma_{\mathrm{SCC}}$. The stress assisted crack-like dissolution preceded by a corrosion pit was produced, leading to the dynamic SCC crack. This shape of the stress assisted dissolved defect (Fig. 10(b)) was remarkably different from the one of spherical corrosion pits.

At the free corrosion potential, SCC cracks were initiated at corrosion pits formed on the specimen surfaces or at the tips of stress assisted crack-like dissolution. Figure 11 shows the relation between the depth of crack initiation sites, $d_{\mathrm{SCC}}$, and $\sigma_{\max }$. It is clear that $d_{\mathrm{SCC}}$ 


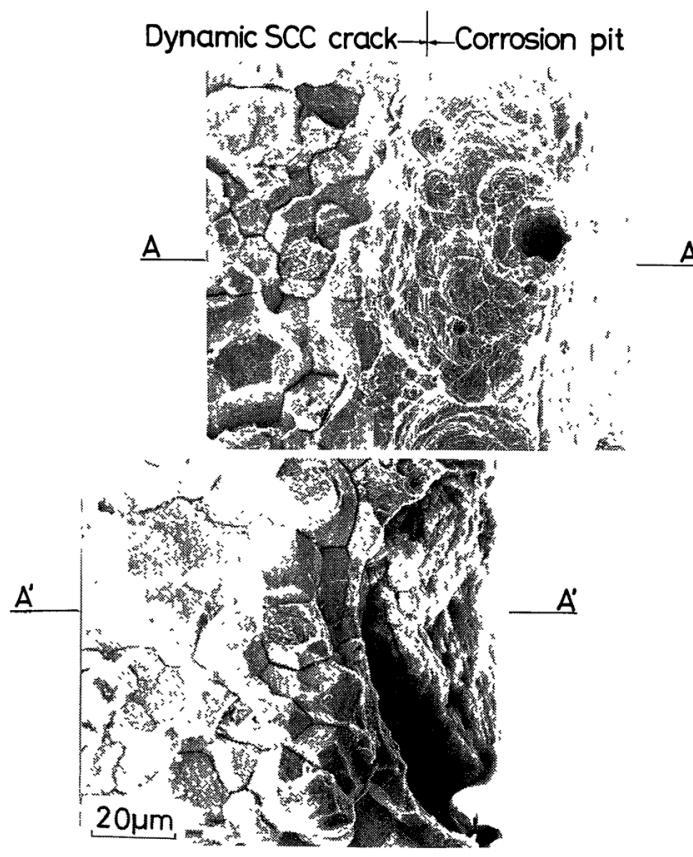

Fig. 9(a) Matching pair of fractographs of the initiation site of dynamic SCC at $E=E_{c}$; a corrosion pit; $f=30$ $\mathrm{Hz}, \sigma_{\max }=1666 \mathrm{MPa}$ and $\Delta \sigma=98 \mathrm{MPa}$.



Fig. 9(b) Matching topography across the A-A and $A^{\prime}$ $\mathrm{A}^{\prime}$ lines of the initiation site shown in Fig. 9(a).

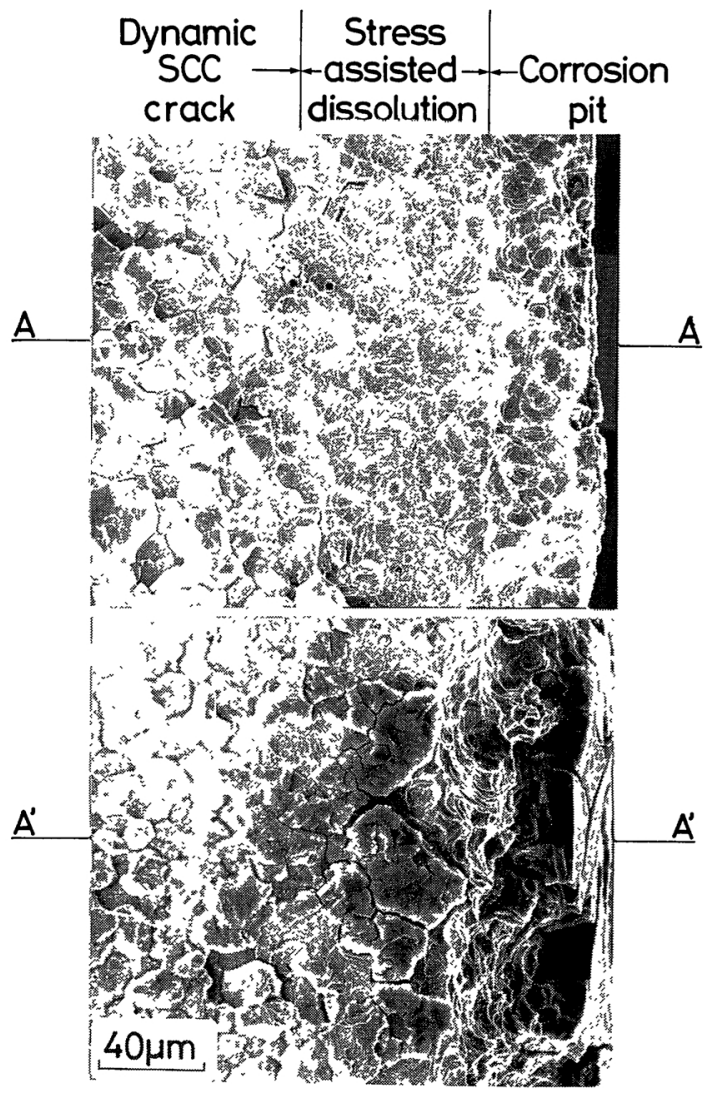

Fig. 10(a) Matching pair of fractographs of the initiation site of dynamic SCC at $E=E_{c}$; stress assisted dissolution; $f=30 \mathrm{~Hz}, \sigma_{\max }=686 \mathrm{MPa}$ and $\Delta \sigma=98 \mathrm{MPa}$.

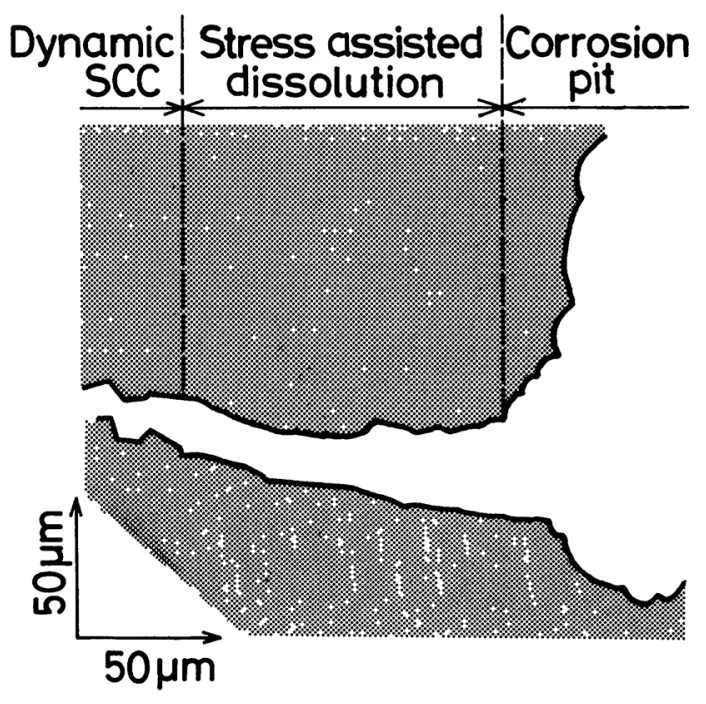

Fig. 10(b) Matching topography across the A-A and $\mathrm{A}^{\prime}$ $A^{\prime}$ lines of the initiation site shown in Fig. 10(a). 


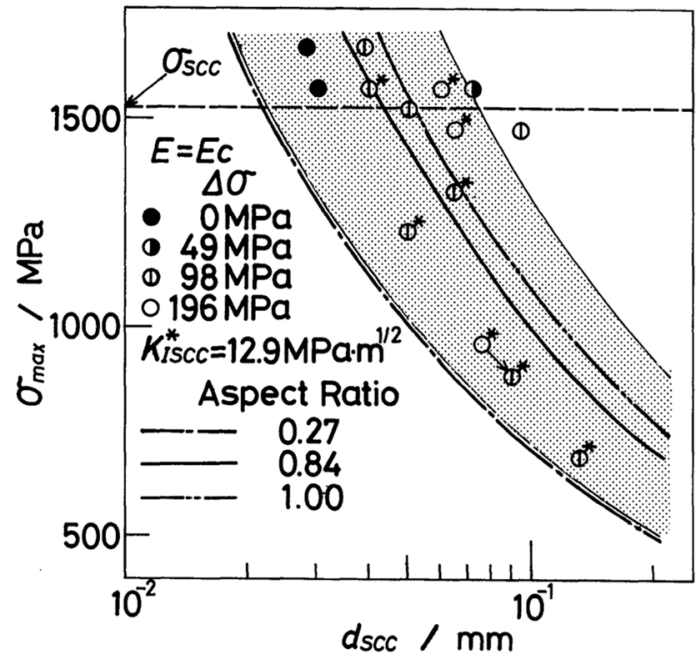

Fig. 11 Relation between $d_{\mathrm{SCC}}$ and $\sigma_{\max }$ at $E=E_{c}$.

became larger with decreasing $\sigma_{\max }$. This was because higher stress concentration was indispensable at lower $\sigma_{\max }$. In the figure, marks with an astrerisk (*) represent that SCC cracks were initiated at the stress assisted crack-like dissolved defects. Whether SCC cracks were initiated at the bottom of corrosion pits or stress assisted crack-like dissolved defects, was determined by the values of $\sigma_{\max }$; SCC cracks at $\sigma_{\max } \geqq \sigma_{\mathrm{SCC}}$ were initiated at corrosion pits, whereas at $\sigma_{\max }<\sigma_{\mathrm{SCC}}$ the initiation sites changed to stress assisted crack-like dissolved defects. Consequently, a fall of $600 \mathrm{ks}$ dynamic SCC strength by small vibratory stresses of $\Delta \sigma \geqq 83 \mathrm{MPa}$ is considered to be caused by the change in the initiation sites from spherical corrosion pits to crack-like dissolved defects.

Figure 12 shows the macroscopic fracture surface of static SCC in the cathodically charged condition. The fracture surface exhibited brittle failures normal to the loading axis, which was the same as those fractured at the free corrosion potential. However, the fracture surface was continuously surrounded by a shear lip, which was different from that fractured at the free corrosion potential. This implies that cracks in the cathodically charged condition were initiated at the interior of specimens.

The fracture surface near the initiation site of the static SCC failure shown in Fig. 12 was

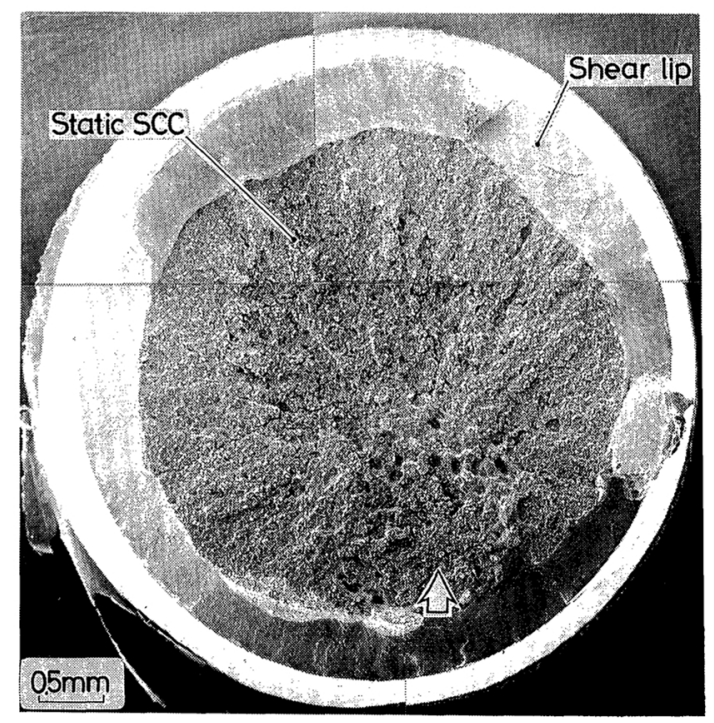

Fig. 12 Macroscopic fracture surface of static SCC at $E=-1.0 \mathrm{~V}$ vs SCE; $\sigma=1690 \mathrm{MPa}$. Arrow shows the initiation site of a static SCC crack.

classified into three types including 1) intergranular cracking (IG), 2) transgranular cracking except dimples (TG) and 3) dimples (Dimple). Figure 13 shows the fracture area fractions as a function of a distance from the surface toward the specimen's center. The fracture surface at a distance of $0.7-0.8 \mathrm{~mm}$ from the surface exhibited intergranular cracking. However, transgranular and dimples came to dominate over the inner and the outer fracture surface. This kind of fracture surface appearances indicates that the crack growth rates were very high and were in the neighborhood

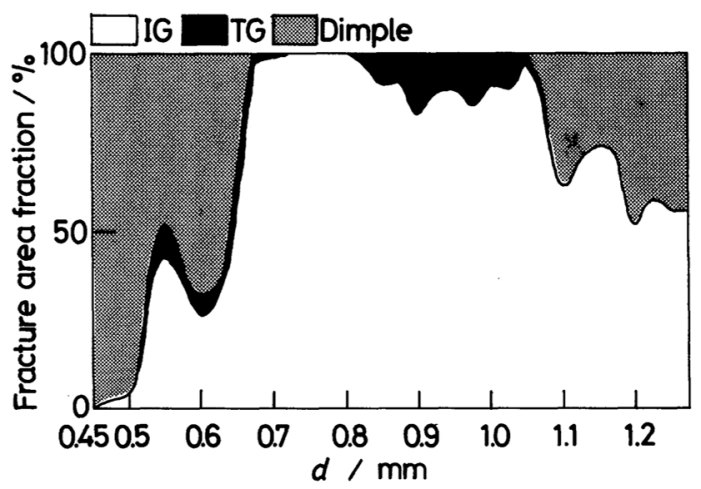

Fig. 13 Variations of fracture area fractions of static SCC at $E=-1.0 \mathrm{~V}$ vs SCE as a function of a distance from the specimen surface; $\sigma=1690 \mathrm{MPa}$. 
of fracture instability, i.e., a final failure. Consequently, static SCC cracks under the cathodically charged condition were initiated at the interior of specimens at a distance of $0.7-0.8 \mathrm{~mm}$ from the surface, and then propagated radiately. Dynamic SCC cracks were also initiated at the interior of specimens in a similar way to static SCC.

In the case of $\mathrm{HE}$ type SCC, the importance of the localized triaxial stress field was emphasized ${ }^{(7)-(9)}$. The maximum triaxial stress owing to the curvature of this specimen existed about $1 \mathrm{~mm}$ inside the specimen from the surface $^{(8)(10)}$, and this position fairly well agreed with that of the initiation site obtained by the fractographical observations. Under the cathodic protection at $E=-1.0 \mathrm{~V}$ vs SCE, corrosion pits, which were observed at the free corrosion potential, were not formed. Therefore, SCC cracks were initiated at the interior of specimens where a triaxial stress was maximum, because hydrogen contents were increased by cathodic current compared with those at the free corrosion potential.

\section{Influence of vibratory stresses on SCC crack initiation}

At the free corrosion potential, static SCC cracks were initiated at the bottom of corrosion pits which grew up to a critical size to ensure enough stress concentration. At $0 \mathrm{MPa}$ $<\Delta \sigma \leqq 74 \mathrm{MPa}$, superimposed small vibratory stresses promoted pit growth, resulting in shorter lives than those of static SCC at $\sigma_{\max }>\sigma_{\mathrm{sCC}}$. However, the influences of vibratory stresses on $600 \mathrm{ks}$ dynamic SCC strength were negligible. In such cases, SCC cracks were readily initiated at the bottom of corrosion pits owing to the maximum stresses being high $\left(\sigma_{\max } \geqq 1530 \mathrm{MPa}=\sigma_{\mathrm{SCC}}\right)$.

At $\Delta \sigma>74 \mathrm{MPa}$ and $\sigma_{\max }<\sigma_{\mathrm{SCC}}$, crack initiation sites changed to crack-like dissolved defects. Figure 14 shows the fracture surface near the initiation site at low $\sigma_{\max }$ and high $\Delta \sigma$. The fracture surface changed with progress of the crack initiation and its propagation: a corrosion pit $\rightarrow$ a stress assisted crack-like dissolved defect $\rightarrow$ transgranular corrosion fatigue (partly with intergranular cracking), which is similar to those observed in the near-

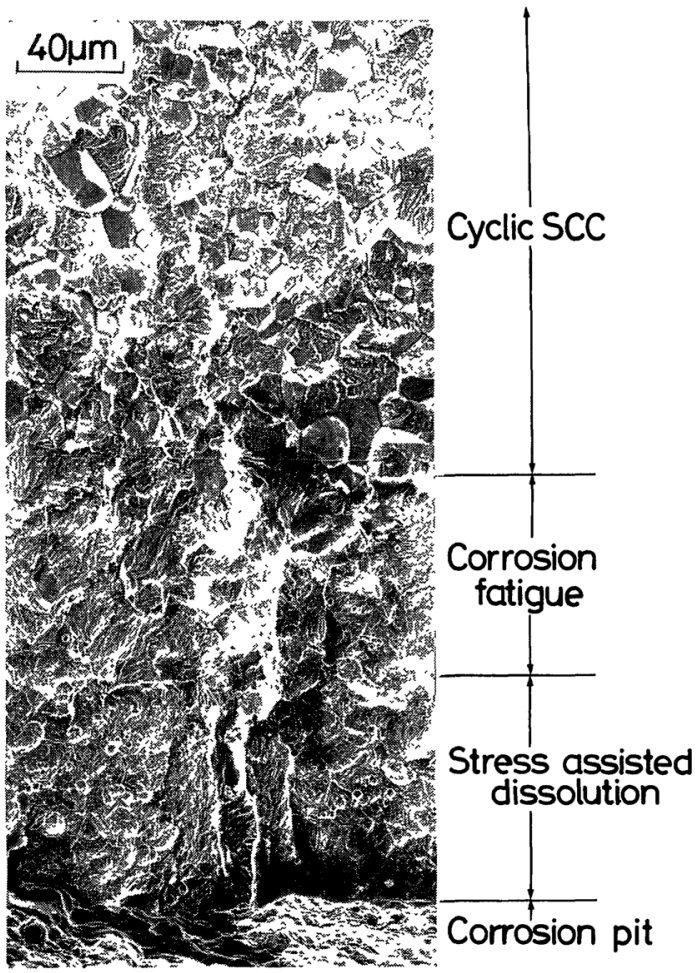

Fig. 14 Fracture surface near the initiation site of cyclic $\mathrm{SCC}$ at $E=E_{c} ; f=30 \mathrm{~Hz}, \sigma_{\max }=490 \mathrm{MPa}$ and $\Delta \sigma=196$ $\mathrm{MPa}$.

threshold region of corrosion fatigue in a highstrength steel ${ }^{(1)} \rightarrow$ inter- and transgranular cracking which is characteristic of cyclic $\mathrm{SCC}^{(11)(12)}$, and finally $\rightarrow$ intergranular cracking which is characteristic of cyclic SCC controlled by static $\mathrm{SCC}^{(12)}$ (a photograph is omitted). These confirm that the stress assisted crack-like dissolution was caused by the same mechanism as crack growth by the stress assisted dissolution observed in long-term corrosion fatigue ${ }^{(13)}$. At higher superimposed vibratory stress ranges of $\Delta \sigma>74 \mathrm{MPa}$, the stress assisted crack-like dissolution was produced at the bottom of a corrosion pit, when it approached a critical size. Namely, when $\sigma_{\max }$ values were large, dynamic SCC cracks were immediately initiated at the bottom of crack-like dissolved defects. At lower $\sigma_{\max }$, on one hand, crack growth mechanisms changed alternately; the first was corrosion fatigue crack growth, the second cyclic SCC (inter- and transgranular cracking), and the last cyclic SCC controlled 
by static SCC. These mechanism changes in agreement with fracture morphology changes. At $\Delta \sigma \leqq 74 \mathrm{MPa}$, the stress assisted dissolution and a fall of $600 \mathrm{ks}$ dynamic SCC strength were not observed within the testing duration of $600 \mathrm{ks}$. However further investigations are required, whether the stress assisted dissolution occurs in longer duration or not.

\section{Application of fracture mechanics to SCC crack initiation at the free corrosion potential}

The depth of initiation sites of SCC cracks, $d_{\mathrm{SCC}}$, increased with decreasing $\sigma_{\max }$. Assuming the initiation sites to be sharp cracks, maximum stress intensity factors at the deepest points, $K_{\max }^{*}$, were calculated using the Newman-Raju equation ${ }^{(14)}$. Here, $K_{\max }^{*}$ values were calculated assuming the thickness to be infinite and the aspect ratio $\alpha$ to be unity when $\alpha>1$. Calculated $K_{\max }^{*}$ values varied from 9.3 $\mathrm{MPa} \mathrm{m}{ }^{1 / 2}$ to $17 \mathrm{MPa} \mathrm{m}^{1 / 2}$, and the averaged value, $K_{\mathrm{ISCC}}^{*}$, was obtained at $12.9 \mathrm{MPa} \mathrm{m}^{1 / 2}$. Figure 11 shows plots of $K_{\text {ISCC }}^{*}$ of $12.9 \mathrm{MPa} \mathrm{m}^{1 / 2}$ for various values of $\alpha$ : The lines represent the $K_{\mathrm{ISCC}}^{*}$ values for $\alpha$ of 0.27 (i.e., the minimum), for $\alpha$ of 1.0 (i.e., the maximum), and for $\alpha$ of 0.84 (i.e., the averaged value). The region at $K_{\max }^{*}$ of $9.3-17 \mathrm{MPa} \mathrm{m}^{1 / 2}$ for the $\alpha$ value of 0.84 is shaded. One can state that experimental points were equal to $K_{\text {ISCC. }}^{*}$ Moreover, $K_{\max }^{*}$ $\left(K_{\mathrm{ISCC}}^{*}\right)$ values fell into the scatter band of threshold stress intensity factors for static SCC obtained by long sharp cracks, $K_{\mathrm{ISCC}}$, which had been reported to be $8-20 \mathrm{MPa} \mathrm{m}^{1 / 2}$ in high-strength martensitic steels immersed in $3.5 \% \mathrm{NaCl}$ solution ${ }^{(9)(15)-(17)}$ (the steels had the same rank of mechanical properties as was used here). These suggest that $K_{\mathrm{ISCC}}^{*}$ obtained by assuming the corrosion pits and the cracklike dissolved defects to be sharp cracks may be adopted as the major mechanical condition whether SCC cracks were initiated at smooth surfaces or not; this method would be very useful to failure analyses as reported on the case history of the Point Pleasant Bridge ${ }^{(18)}$. Here, one should note that $K_{\text {ISCC }}^{*}$ is not the " $K$ " value in the strict sense because of neglecting the radii of tips and the applicability of the " $K$ " concepts to short cracks.

\section{Conclusion}

The influences of vibratory stresses on dynamic SCC crack initiation behavior have been investigated on a high-strength steel sensitive to HE type SCC, and the following have been made clear:

(1) The AE monitoring technique is powerful to detect SCC crack initiation and its propagation in such a high-strength steel as was used in this experiment.

(2) At the free corrosion potential, the time to crack initiation with vibratory stresses superimposed is shorter than that of static SCC with lower $600 \mathrm{ks}$ strength than $\sigma_{\mathrm{SCC}}$. At $\Delta \sigma \leqq 74 \mathrm{MPa}$, however, the effects of superimposed vibratory stresses on $600 \mathrm{ks}$ strength are negligible with the same value as $\sigma_{\mathrm{SCC}}$.

(3) At $\sigma_{\max } \geqq \sigma_{\mathrm{SCC}}, \mathrm{SCC}$ cracks are initiated at the bottom of corrosion pits formed on the surfaces. Superimposed vibratory stresses promote growth of corrosion pits, leading to shorter lives than those of static SCC.

(4) At $\sigma_{\max }<\sigma_{\mathrm{SCC}}$ and $\Delta \sigma>74 \mathrm{MPa}$, dynamic SCC cracks are initiated at the bottom of stress assisted crack-like dissolved defects preceded by corrosion pits. Superimposed vibratory stresses enhance stress assisted dissolution, leading to both shorter lives and lower $600 \mathrm{ks}$ strength.

(5) Under the cathodically charged condition, the effects of superimposed vibratory stresses on $600 \mathrm{ks}$ strength are negligible, because any metal dissolution reaction is inhibited; corrosion pits or stress assisted dissolution is not brought about. In this case, the hydrogen contents are increased by the cathodic current, and therefore, SCC cracks are initiated at the interior of specimens where the triaxial stress is maximum.

\section{REFERENCES}

(1) K. Endo, K. Komai and K. Minoshima: Proc. 25th Japan Congr. Mater. Res., JSMS, (1982), 56.

(2) K. Endo, K. Komai and K. Minoshima: Proc. Fatigue '81, (1981), 77, SEE.

(3) K. Komai and K. Minoshima: Proc. Inter. Congr. Metal. Corros., 1 (1984), 107.

(4) K. Nakasa, M. Kido and H. Takei: J. Japan Inst. Metals, 40 (1976), 744 (in Japanese). 
(5) M. Kido, K. Nakasa and H. Takei: J. Iron Steel Inst. Japan, 65 (1979), 535.

(6) C. H. Sondergeld: Rev. Sci. Instrum., 51 (1980), 1342.

(7) C. St. John and W. W. Gerberich: Met. Trans., 4 (1973), 589.

(8) H. H. Johnson, J. G. Morlet and A. R. Troiano: Trans. Met. Soc. AIME, 212 (1958), 528.

(9) H. R. Smith, D. E. Piper and F. K. Downey: Eng. Frac. Mech., 1 (1968), 123.

(10) S. Fukui and C. Asada: J. Iron Steel Inst. Japan, 54 (1968), 1290.

(11) K. Endo, K. Komai, T. Fujimoto and Y. Matsuda:
Bulletin Japan Soc. Mech. Engrs., 23 (1980), 807.

(12) K. Endo, K. Komai and Y. Matsuda: Bulletin Japan Soc. Mech. Engrs., 24 (1981), 1885.

(13) K. Endo, K. Komai and S. Kinoshita: Proc. 22nd Japan Congr. Mater. Res., JSMS, (1979), 193.

(14) J. C. Newman and I. S. Raju: NASA TP-1578, (1979).

(15) G. Sandoz: Met. Trans., 3 (1972), 1169.

(16) C. S. Carter: Met. Trans., 3 (1972), 584.

(17) Y. Hirose and K. Tanaka: J. Soc. Mater. Sci. Japan, 29 (1980), 822.

(18) J. A. Bennett and H. Mindlin: J. Test. Evalu., 1 (1973), 152. 